\title{
Developing a Methodology to Assess Children's Perceptions of the Tropical Environment
}

\author{
Reesa Sorin ${ }^{1} \&$ Iain J. Gordon ${ }^{2}$ \\ ${ }^{1}$ School of Education, James Cook University, Cairns, Australia \\ 2 James Hutton Institute, Mylnefield, Invergowrie, Dundee, DD2 5DA, UK \\ Correspondence: Reesa Sorin, School of Education, James Cook University, Cairns, Australia. E-mail: \\ reesa.sorin@jcu.edu.au
}

Received: November 26, 2012 Accepted: December 10, 2012 Online Published: December 20, 2012

doi:10.5539/ies.v6n2p96

URL: http://dx.doi.org/10.5539/ies.v6n2p96

\begin{abstract}
Australia holds some of the most unique, diverse and vulnerable ecosystems in the world, ranging from marine, coral reefs, to the arid and semi-arid outback, to tropical rainforests. Young children's perceptions of, and attitudes to their environment carry with them into adulthood, determining their capacity to learn about and interact with their world. To sustain Australia's unique landscapes it is essential that these future adults have an informed knowledge of the role, value and function of the country's environment. To ensure that we are helping the youth of today understand the natural environment we must first determine their current perceptions of it.

This research describes an Arts/Science nexus; while traditional data collection methods, such as surveys, interviews and focus groups are often used to determine children's understandings, these methods are limited by their reliance on words. Children, particularly young children, do not always have the words to describe what they see, think or feel. The Arts, however, can be used as tools to help children express their ideas and feelings. So our research question was: how can we use an arts-based methodology to determine children's perceptions of their environment?

To answer this question, five arts-based strategies were trialled, tested and refined. This article elucidates these different strategies, including the methods used and the impact of these methods on children's expression of their environmental understandings. It concludes with a description of the researchers' key learnings relating to arts-based data collection methods to determine children's environmental perceptions.
\end{abstract}

Keywords: arts-based data collection, early childhood environmental understanding, environmental sustainability

\section{Introduction}

Australia holds some of the most diverse and vulnerable ecosystems in the world, ranging from the marine, coral reefs, to the arid and semi-arid outback, to tropical rainforests (Westoby, 1993). These ecosystems are composed of unique biodiversity that has evolved on this continent for millennia and provides ecosystem services (e.g. clean air, clean water, primary production) that sustain Australians today (Millennium Ecosystem Assessment, 2005).

To maintain Australia's ecosystems and the services they provide, it is essential that the children of Australia have an understanding about the role, value and function of the country's environment. The attitudes and perceptions they carry with them into adulthood determine the ways in which these adults of tomorrow will interact with their world (Ewert, Place \& Sibthorp. 2005). Attitudes and perceptions are formed through children's interactions with the world, their education and the society and environment in which they live (Olli, Grendstad \& Wollebaek, 2001; Steadman 2002; Villacorta, Koestner \& Lekes, 2003). To ensure that we are helping the youth of today to understand and protect the natural environment we must first determine their current perceptions of it.

Arts-based research is a qualitative tool that can involve using the arts as a method, subject, form of analysis, or all of the above (Huss \& Cwikel, 2005). Sorin (2004) explains that children, particularly young children, do not always have the words to describe what they see, think or feel. The Arts, including visual art, drama, dance, music and media, can be used as tools to help children express their ideas and feelings. As Cornett (2007) notes, 
"The arts are viewed as indispensable sources of cultural and historical information, givers of diverse perspectives and values and remarkable tools to make meaning" (p.2). In the last decade we have witnessed an 'explosion' of arts-based forms of research (Mullen, 2003).

Arts-based methodologies evident in the qualitative literature include dance, implemented by Torzillo (2009) to express her data findings; photo elicitation used as a tool in several studies to evoke children's and adult's memories and experiences of place/s (Benson, 2009; Kyle \& Chick, 2007); and combinative methods, such as Somerville's (2008) methodology, which used the visual arts (paintings, photographs), storytelling (oral and written) and ICT's (dvds, audio) to represent people's place relationships and stories. However, of all the artistic mediums, it appears as though drawings are those most commonly used in research with children about their environments (Alerby, 2000; Barazza, 1999; Bowker, 2007).

The power of visual narratives for exploring 'big ideas' have been potent throughout history and it is widely recognised that "the content of children's drawings may provide insight into their thoughts and feelings about the world" (Barazza, 1999, p.49). Barazza (1999) used drawings as a research tool on several occasions to ascertain Mexican and English children's environmental understandings and awareness; Alerby (2000) asked children to complete drawings representing what they thought of when they heard the word 'environment'; and Bowker (2007) had children complete drawings both prior to and after completing a unit of work on tropical rainforests to measure children's environmental learning.

Anning \& Ring (2004) note that children's creativity is syncretistic, meaning the individual arts have yet to be separated and specialised; therefore children are likely to draw pictures and tell a story at the same time. They suggest that young children's narratives offer tools for them to organise and explain their complex worlds. Drawings combined with storytelling enrich and inform each other (Wright, 2008). By sharing stories about their environments children give order, significance and meaning to the chaos of their experiences (Blizard \& Schuster, 2007). Drawing and story-telling combined, then, appear to provide a holistic, art-based research tool that allows children to represent their multiple meanings in verbal and non-verbal ways.

Unfortunately, arts-based methodologies are often overlooked and/or undermined, "perhaps from misdirected assumptions on a practical level surrounding content and delivery... [but also because] the Western bias towards linguistic intelligence means that skills which utilise embodied practice and body intelligences tend to be denigrated" (cited in Knight, 2008, p.307). Rose (2007), highlights that despite the huge amount of academic work being published on the visual, there remain remarkably few guides to possible methods of interpreting visual materials, and even fewer explanations of how to actually conduct these methods. With this in mind, our research question was: How can we use an arts-based methodology to determine children's perceptions of their environment?

The aim of this research was to develop and refine methods for ascertaining young children's perceptions of the environment in which they live. Five arts-based strategies were trialled and evaluated to determine the best methods for eliciting children's perceptions of the environment. Methods included: presenting children's picture books; using props; drawings; storytelling; dramatising and introducing an authentic task.

This article describes the five different arts-based strategies and the impact of these methods on children's expressions of their environmental understandings. It concludes with a description of the key learnings researchers uncovered, relating to effective and ineffective data collection methods used when implementing an arts-based methodology to determine children's environmental perceptions.

\section{Method}

The research question of this study was formulated collaboratively by combining the interests and backgrounds of two very different professionals: an ecological scientist, interested in children's environmental understandings; and an Early Childhood/ Arts lecturer. We established a partnership, focused on ascertaining what young children understand about their environment and the best ways in which to elicit these understandings from them. Resulting from this joint effort, the following research question, "How can we use an arts-based methodology to determine children's perceptions of their environment?" evolved.

Our journey to generate data relevant to the research question took us to a number of different classrooms, year levels and locations. Over one hundred children, aged from 5-15 in urban, rural and remote schools were involved. These schools included state and private schools in north Queensland and an international school in the Philippines. Five arts-based strategies for collecting data about children's perceptions of the environment were developed, trialled and refined. Data collected included children's drawings, their verbal accounts of the drawings, and teacher and researcher notes. 
To develop, trial and refine various arts-based data collection methods, researchers implemented an Action Research approach. This involves researching a practical issue using a cyclical process, with the implications of this approach being that the research process is ongoing, and changes to methods occur to improve results, thus improving its applicability to real-world situations (Denscombe, 2007). The steps involved in the cycle are found in the diagram below. Each of the five arts-based strategies was implemented, by the researchers, and evaluated, with input from classroom teachers and school principals, based on its strengths and aspects in need of change. A discussion of the action research process of this study is presented in the next section. Below is a model of the Action Research Cycle (Department of Families, Housing, Community Services and Indigenous Affairs [FaHCSIA], (2009)):

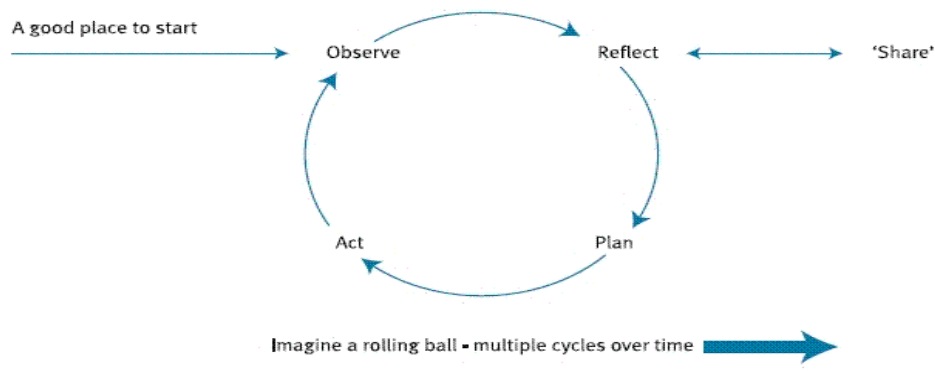

Throughout each of the five arts-based strategies paper size, length of time to complete the task, age of participants, types of school-based settings, drawing materials and elicitation methods were modified in order to develop the most effective method. The researchers acknowledge these inconsistences as impacting on the reliability and validity of this study's findings. It is however, important to note that qualitative research should not be judged on positivist notions such as reliability and validity but on an alternative criterion known as trustworthiness (Lincoln \& Guba, 1985). Trustworthiness was established in this study through the use of techniques such as member checking and triangulation (credibility); and through use of thick detailed descriptions of the phenomena under study so that future research findings can be compared and/ or replicated (transferability). Throughout each of the cycles the researchers have reflected collaboratively on the research process, maintaining an audit trail of each strategy in order to address criterion related to the dependability and confirmability of the study. We do, however, acknowledge the difficulty in remaining completely objective in qualitative research, thus noting the influence of our own interpretive subjectivities.

In addition to the action research cycle, data, in the form of children's drawings and stories, were analysed based on up to two factors - the content of the drawings (using quantitative content analysis); and the general mood and feelings attributed to their environmental depictions (using qualitative coding). Findings generated from the data analysis highlighted the strengths and weaknesses of particular arts-based methodologies, adding to the evaluative and reflective action research cycle. A discussion of the five arts-based strategies and how they were developed and refined using the action research cycles follows.

\section{Results}

\subsection{Strategy 1: Drawing/ Counting}

The first phase of this research used a Drawing/Counting strategy for data collection and analysis. Few people acknowledge that "drawings can be used to demonstrate unimaginable conceptual understandings in ways that cannot be expressed through language" (Kress, 2000, cited in Kendrick and McKay, 2004, p.124).This initial phase of research was conducted by one of the researchers independently, as it was conducted before the two had met.

Primary and middle school-aged children, 7 - 15, in north Australia and in an international school in the Philippines, were asked to draw the environment as it is today; as they think it will look in 20 years; and as they would like it to look in 20 years. Each child was given a long sheet of paper with instructions at the top, and three A4 -sized rectangles (Figure 1). Drawing materials were standardised so that each student was given an identical set of coloured pencils. The children were given 20 minutes to complete each of their drawings. 


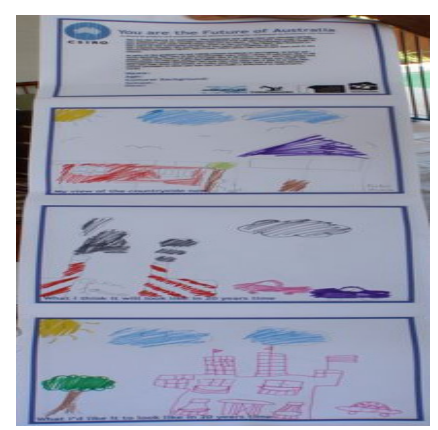

Figure 1 .

At the end of the allotted time, drawings were submitted to the researcher. Quantitative content analysis was conducted, with information such as the number of houses, trees, cows and plants counted in each of the three rectangles. For the most part, human-made objects dominated the drawings in response to the question of what the world would look like in 20 years from now; whereas natural objects, such as plants and animals, were more prolific in drawings of how children would like their future environment to look in 20 years.

The Drawing/Counting strategy standardised the way in which information was collected from children and ensured that there was not inherent bias in the way material was gathered. While detailed content information was evidenced through this strategy, there was no supporting information about what children were trying to represent or feeling about their drawings and the environment. This presented as problematic, particularly with drawings by young children (aged $7-9$ ), which were often difficult to understand. Drawings may have been better understood if the researcher had interacted with the children and taken notes during the drawing-making process. Wright (2008) highlights it is not the strategies, skills and end product of children's drawings that matter, but the drawing-making process itself. All aspects of that process need to be considered including the reason, meaning, graphic, narrative and embodied dimensions of the experience.

The three A4 size rectangles may have restricted what could be added to the drawings. Particularly with the older children, drawings were very crowded and seemed to extend beyond the rectangle. Therefore, in the next strategy, we decided to increase the paper size to A3.

Finally, it was noted from the detail in many drawings that many of the older children seemed well-informed about environmental sustainability, either directly through their schooling or indirectly through the media. This learning was reflected in those drawings that included a present-day depiction of pristine, untouched environments and a future depiction of overly-developed ones. For the purpose of this study, researchers were interested in child participants whose environmental conceptualisations were minimally affected by previous schooling and/ or media representations, thus the decision to focus on an early childhood cohort in future strategies.

Based on the above issues and the researcher's inexperience with analysing children's art, the researcher decided to bring an art and childhood expert on board to improve the data collection process and it was with Strategy 2 that the researchers began collaborating.

\subsection{Strategy 2: Children's Picture Book, Window Frame, Drawing and Voluntary Storytelling}

The second strategy was our pilot study as a collaborative team. We shifted the research strategy to a voluntary "drawing telling" approach, where "drawing is used to describe children's use of a range of signs when depicting imaginary worlds on paper" (Wright, 2007, p.37). In particular "drawing telling” involves children in a process whereby they switch between the use of verbal and non-verbal modes of communication in order to best represent the meanings they would like to get across. Cox (2005, p.123, cited in Wright, 2007, p. 38) describes it as follows:

Talking and drawing interact with each other as parallel and mutually transformative processes. Sometimes the talking feeds into the drawing with the verbalised intention being transformed into drawing. Sometimes the drawing feeds into the talking; the drawing intention is transformed into talking. Sometimes these processes are apparently concurrent.

A key concern we had with Strategy 1 was that children's environmental perceptions were difficult to understand from their drawings alone. We decided to add storytelling, on a voluntary basis, to the process. By using the "drawing telling" approach, we felt we would be better able to understand children's current perceptions of the environment and their predictions for the future. Indeed, as Wright (2001) proposes, when children's 
environmental drawings are accompanied by stories, researchers can be provided with a window into children's outlook, and whether they view the future optimistically, pessimistically, fatalistically, futuristically, or in other ways.

Children in a Year 2 class (6-7 year olds) in urban Australia were asked to construct a drawing of their present-day landscape and a drawing of what they imagined their landscape would look like 20 years into the future. The decision to focus on younger children was based on research findings suggesting that positive environmental attitudes develop some time during early and middle childhood (White, 2004) with 50-80\% of environmental activists identifying childhood nature experiences as significantly impacting on their career choice and sustainable lifestyle (Chawla, 2007).

Time was extended from the previous 20-minutes per drawing to a half-hour per drawing to accommodate the larger paper size and allow more flexibility than in Strategy 1, where the A4 size seemed to restrict what could be drawn. Drawing materials consisted of drawing pencils, coloured pencils, crayons and felt-tipped pens. Each table of children were given a container of these materials to share amongst themselves. The variety of drawing materials increased because providing open-ended materials allows children choices and independence, both crucial in stimulating genuine creativity (Drew \& Rankin, 2004).

The researchers introduced the data collection session by reading and discussing the wordless picture book, Window, by Jeannie Baker. Baker's Window is often used by educators to introduce environmental topics because, as Linon, Outhred \& Farrell (1999) emphasise, children's environmental awareness can be increased by using literature to start a discussion in the classroom. Window tells the story of a boy growing up in an increasingly industrialised landscape. Butler (2008) describes the story as follows:

In the first panel a woman stands at the window, holding a baby, looking out at bush teeming with bird life and plants, with wooded hills beyond. The double-page spreads follow the view from the window as the baby grows up. And as he grows, the landscape seen through his window changes, reflecting the impact of the expanding community.

The trees and birds gradually disappear, to be replaced by houses, roads and supermarkets. The last panel, showing the grown-up baby holding his newborn child as he looks through a different window at a pristine piece of bush set aside for a housing estate, brings the 'story' back to the beginning.

Using the concept of the window frame, as exemplified in the story, the researchers followed up the book discussion by giving each child a cardboard square (window frame). Children were asked to imagine and then draw what they could see in their environment from their window frame. Children used the materials provided, but also brought out rulers from their desks to draw window frames in their pictures.

As they completed their drawings, the researchers and classroom teacher engaged as participant observers, circulating and writing down children's comments in a notebook or on children's work if they requested. Note-taking was a process used by the researchers consistently in the remainder of the strategies. Children who finished their drawings while the researchers were present in the class showed their work to their classmates and described what was in the drawing.

Those who had not finished were allowed to complete their drawings at a later time. Edwards \& Nabors (1993) note that art-making is a creative process that takes time and that children should be encouraged to return to a project and work on it until they feel it is completed. Drawings were collected from the teacher in the following week, but with no clear indication of the time taken to produce them. The teacher used the cardboard window frames in further arts and science lessons, as a way of getting children to look carefully at objects in their environment.

Content of the drawings was examined quantitatively for the presence or absence of natural and human-made objects, and qualitatively for the elements of design and the mood they conveyed. Children's drawings represented a wide variety of human-made, and natural objects, and conveyed changing moods between their present and future drawings, using the elements of design. However, the most notable feature of children's drawings, was the presence of a drawn-in window frame, much like the Window book.

Many drawings included the window frame and children drew literally what they saw when they held the frame in front of their faces, including views of the classroom and school grounds. The natural landscape in which they lived was present in only a few drawings. Instead, there were scenes from the classroom, such as the desks, chairs and books, and some indication of a tree or two outside the classroom window. Drawings that featured the window frame appeared restricted with the window outline creating boundaries of what could and could not be 
featured in the drawing (Figure 2 below). From this experience, it was felt that the cardboard window frame had too great an influence on the drawings and should be omitted from any further strategies.

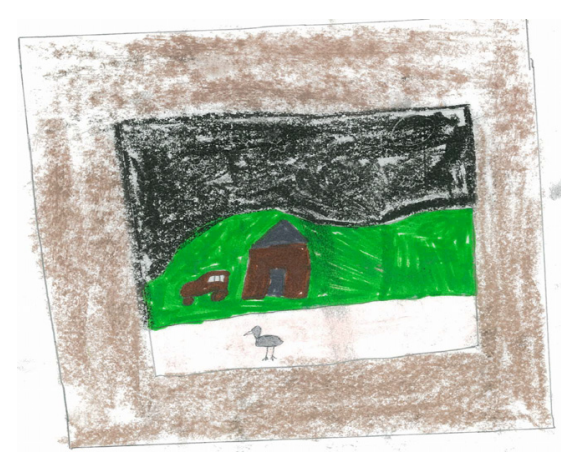

Figure 2.

With no real time restriction, drawings that were completed over a longer period of time showed more detail than those completed with the researchers in class. Children who took extended time to finish their drawings could have discussed their drawings with others outside of the classroom and it was recognised that this may have influenced their final creations and thus what we determined about their environmental perceptions.

Early childhood is a significant period of life, where the foundations for one's life are built. We reflected that including younger children in the research was beneficial, because children's conceptualisations in this period are formative (Elliott, 2003), thus less influenced by prior teachings on environmental sustainability and societal opinions. From their discussions and stories, it seemed that many children had not yet learned much about environmental sustainability. For example, a number of children thought it was better in the story when the trees were cut down and more buildings appeared in the landscape. However, it is important to note, that we could not ascertain all children's prior learning and pre-existing environmental conceptualisations, because some drawings did not feature an accompanying story, which made them difficult to interpret and analyse.

For the next action research strategy, we maintained the idea of using the book, Window, as an introduction, A3 sized drawing paper, and the same variety of drawing materials.

\subsection{Strategy 3: Children's Picture Book, Drawing and Voluntary Storytelling}

Strategy 3 of this study was similar to Strategy 2, but with minor changes. We still used the book, Window, and the same drawings materials, but omitted the cardboard window frame as a way to encourage children to be more imaginative. Children involved were from a private school lower primary class ( 5 to 8 year olds) in a rural state school and a private urban school in Australia. The study sample was enlarged and diversified to increase the transferability of the study's findings.

After an approximately $1 / 2$ hour introduction, using the Window book, children were given one hour to complete two drawings: one representing children's current environment and the other how children thought their environment would look in 20 years. Children, after completing their drawings could tell a story, write words about the drawings, share it with classmates, or, as it is recognised that not all children wish to share a story, simply hand them in. In the previous phase, Strategy 2, it was identified that those children who had extra time to complete their drawings may have been influenced by outside sources; therefore drawings in this phase were handed in whether completed or not to avoid possible external influences.

Drawings were matched so that each child's present and future drawings were placed side by side in a folder. They were analysed both quantitatively and qualitatively. Upon first examination of the pictures, we developed quantitative categories that encompassed the major classifications of items in the drawings. In all there were 16 categories including trees, people, domestic and wild animals, houses, buildings, vehicles, water, roads, sun, vegetation and windows.

One of the researchers then went through all of the drawings individually and completed a quantitative content analysis. Quantitative content analysis is a method used to analyse any sort of text, by means of quantification (Denscombe, 2007). Prior to quantification, the development of relevant categories takes place and to complete the process, the presence, or absence of particular categories in the drawings are noted. Quantitative content analysis allowed comparison of children's perceptions of the present and their outlook for the future. 
Qualitative analysis was applied to the drawings, based on the elements of design (line, shape, texture and colour) and the mood of the picture. It is important to consider these elements as children "assemble these basic visual signifiers in their texts to make meaning and to produce sensations that carry emotional undertones or connotations metaphorically" (Wright, 2010, p. 82). The two drawings together were examined for changes they demonstrated, such as going from many trees to no or one tree, or changing from a "happy" scene to an "unhappy" one. Written stories by some children and comments recorded by the researchers were added to children's work to provide a deeper understanding.

Many drawings of the present environment were filled with organic lines and shapes, bright colours, flora-filled settings, animals and happy, smiling people. As in previous stages, many children portrayed the future environment pessimistically in terms of a lack of natural features. There were fewer trees and plants and less water (all valuable natural resources) in the future drawings and an increase in people and buildings. This may have been due to prior learning or the influence of the book, Window. Future drawings presented sharper, geometric lines and shapes, darker colours and the replacement of living with non-living objects.

Use of space often changed between drawings. The open spaces represented in the first drawing became more crowded in the second drawing. Because of changes in colour, shape, facial expressions, objects in the environment and use of space, mood changes were apparent in many pictures and most pictures reflected the negative changes depicted in the book, Window. But not every student portrayed the future as bleak - for a small number of children the future was similar to or even better than the present. We also found that some children's drawings seemed to represent their own interests, such as Thomas the Tank Engine, rather than demonstrating their perceptions of the environment.

In our reflections, we noted that the influence of the book, voluntary storytelling, time and material constraints were issues that we needed to consider and adapt in our next strategy.

Window is a powerful book. Through beautiful illustrations and without words it tells a story about the destruction of the natural environment. Its message is clear, and while this may have helped to introduce the idea and to focus children's attention on the issue of environmental sustainability, it left little room for other perspectives, such as that building up residential areas is good, or at least necessary, development. Environmentalists may want children to understand the importance of sustaining natural environments, but as a research technique it seemed to bias children's depictions, rather than providing us with a true glimpse of their perceptions.

Each page of the book, Window, is presented as a view through a window frame and even without the use of a cardboard window frame some children still attempted to model this idea by drawing or carefully ruling a window frame onto their paper. Rulers were not provided to children for this activity, but as they were in their classrooms they had access to items at their desks. Furthermore, the influence of the Window concept prompted some children to draw literally what they could see from their windows at home, which in one case, was a tall fence blocking the view of the surrounding environment (Figure 3 below).

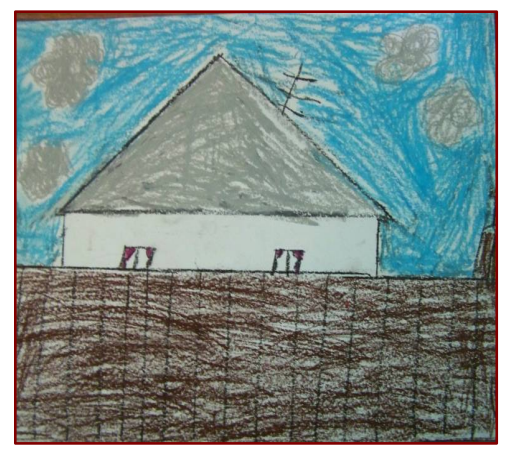

Figure 3.

Stories about children's drawings were optional, because not all drawings have a story, nor do all children wish to tell a story about their drawings. Early drawings are often ways that children explore elements of design, such as colour, line, shape and texture, and experiment with the concept of working within a confined, usually rectangular space. This spatial exploration is often a precursor to writing, where children are required to shape letters in specific ways and to fit within the parameters of the line and page (Tassoni, 2007). 
With storytelling voluntary, some of the drawings that were not accompanied by stories were difficult to understand. Those children who did share a story about their drawings enriched our understandings of their drawings. For example, M. drew a picture of tree-filled, rolling hills and two small houses to the side. Her story was: In the morning I wake up and go for a walk and go to school. I see trees and houses and flowers. I see hills. (Figure 4 below).

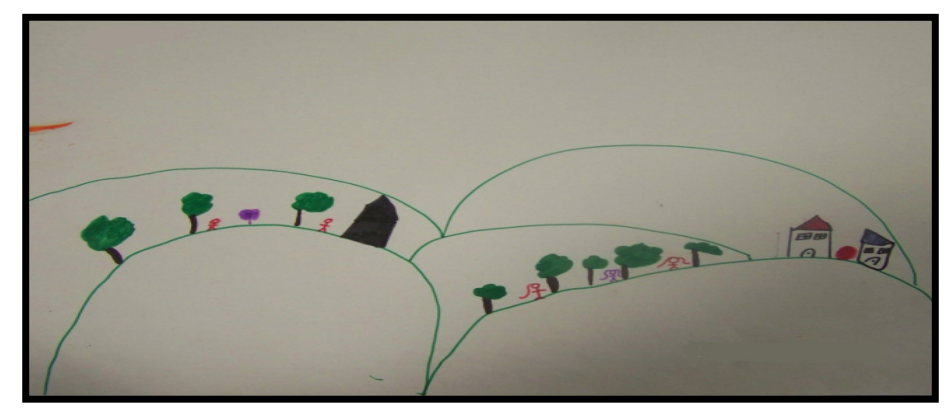

Figure 4.

Her story confirmed for us that it was a genuine experience, rather than something gleaned from the picture book.

Time and materials were identified in this strategy, as possibly limiting children's drawings and perhaps causing misrepresentation of the environments they were trying to describe.

Initially, this presented an issue in relation to a child's concept of time. Not all children seemed able to conceptualise the future, particularly those in the younger grades. In his drawing of the future, a Preparatory student (4-5 years) drew five small squares on the paper and wrote: "I have no I dey [idea] no" (Figure 5 below).

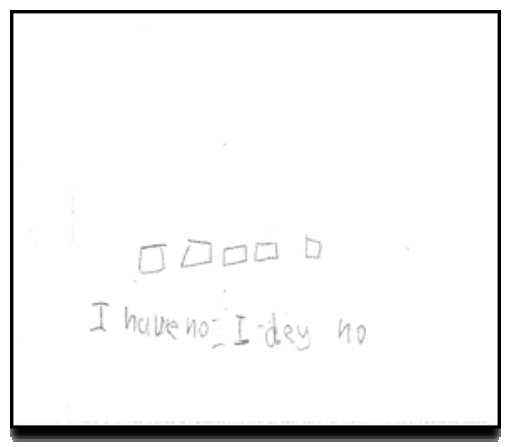

Figure 5.

The concepts of time: past and future are abstract, and not all young children seemed to be able to conceptualise the future and what it would look like. We used terms such as "when you are a parent", or when you are 26 (if the student was 6) to try to help them to conceptualise, but some clearly were unable to do so.

Time constraints may also have been the reason why some children' first pictures were colourful and their second ones were not. For example, B.'s first picture utilised dark green, red and brown as he presented rounded hills, a sun, clouds and trees, alongside more angular cars, buildings, a road and a rocket. His second picture was much more angular, with three of the four people looking very angry. The only colour used was red and the picture was largely uncoloured. B's story of the second picture was that it was "red hot and angry", so perhaps the solitary colour was what he intended, or perhaps he was limited by the allocated time given to complete both drawings.

Finally, it was noted in this stage that the assigned materials may also be impacting on the quality of children's drawings. We offered a variety of drawing materials ranging in size (thick or fine), including coloured pencils, textas, and crayons to cater for the ages of children. However, children had to share supplies with others at their tables, so usually 4 or 5 children shared one container of drawing materials. This was problematic because 
limiting children's colour and material choices when they needed to complete their drawings on large A3 sheets of paper, under restricted time circumstances seemed difficult for some children.

\subsection{Strategy 4: Drawing, Storytelling and Dramatisation}

Reflecting upon Strategy 3, we noted that those drawings that were accompanied by a story gave us a great deal more information than ones without a story. Thus, we decided that storytelling would no longer be optional, but a requirement. The class chosen for this stage of the research was a Preparatory to Year 3 class (5-8 years) in a small, remote State school (giving us in total, experience in urban, rural and remote contexts) in Australia.

In this strategy, the introductory task, using the Window book was replaced by a dramatization. As Ewing (2010, in Russell-Bowie, 2012) notes, "Drama can effect change in social behaviours, because it provides opportunities for learners to explore multiple perspectives and work through real issues and dilemmas in fictional contexts" (p. 241). As researchers we became tourists from overseas (fortuitously one researcher is from Scotland and the other from Canada), unfamiliar with this new environment and wanting to know more about the local area, particularly the local wildlife. We presented our dilemma to the class, who easily engaged in discussion with us.

Children in the class gave us quite a lot of information, and agreed to do drawings and to dictate or write a story about their drawings. They were given A3 paper and the same drawing materials as in Strategy 3, but in this stage, children were able to use additional classroom resources such as paint and various-sized paper. All children shared their work with the researchers or teacher and the class. With children's instructions about where to locate frogs and other local wildlife, and with their drawings in hand, the researchers left the class to look for the wildlife.

As part of the dramatization, the researchers returned later in the day, having seen wombats and birds, but disappointed that they had not seen any frogs. The children were eager to help, so took the researchers outdoors to the school toilets, where frogs could be seen in the drain pipes. Some children drew further pictures for the researchers, including drawings of the frogs in the drains. These pictures were created entirely by choice with classroom materials, including A4 paper, paint and pencils (Figure 6).

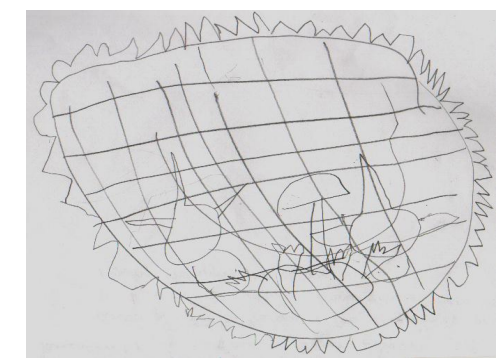

Figure 6.

Drawings from this session were examined using the analysis techniques described previously - quantitative content analysis, elements of design and mood. Requiring children to share stories about their drawings made a great difference to our ability to understand the drawings. For example, one student did a drawing of several trees, with two hanging objects (Figure 7 below). Her story was: "These are the bats hanging in the trees. When we went there we had some lunch and we saw some bush turkeys. When we left they hopped on the tables and ate all of the scraps that we left behind."

Without the student's story we would have missed much of the rich detail that she had thought about when completing the picture. Stories then appear to be indispensable to understanding the meanings associated with children's drawings. Indeed, as Benson (2009) highlights, the key to enabling children to communicate through drawings is interpretation, which requires discussing the drawing with the child to reveal their own intended meanings and interpretations. 


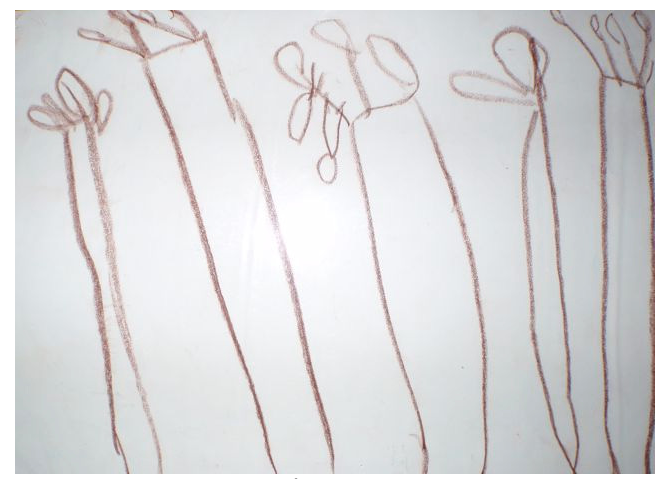

Figure 7.

Dramatisation was considered a successful strategy for introducing the data collection process, as children engaged easily with the scenario presented. The researchers arrived at the classroom as tourists with a genuine interest in the local environment. This created an authentic pedagogic situation, which refers to tasks that call upon children to construct knowledge, through inquiry, addressing problems that have meaning to the child's life beyond the school setting (Newman, Marks, \& Gamoran, 1995). The down side was that future contact with the children would require the researchers to stay in their roles to maintain credibility.

Children's preference for classroom art supplies, such as paint and smaller paper, was another issue for us to consider. Using paint and thick brushes, they were able to easily complete drawings on A3 paper. But with our original drawing materials, many of the larger drawings appeared incomplete, or focused on a small section of paper only. When they were able to choose papers, they generally chose smaller paper to use with our drawing materials.

\subsection{Strategy 5: Drawing; Storytelling; Dramatisation and Introducing an Authentic Task}

When we left the remote school in our dramatized roles, we promised to stay in contact, even when we were "far away" in Scotland and Canada. To do so, one of the researchers wrote a postcard and had it sent to the children from Scotland. In it he described the Scottish landscape and lifestyle as well as thanking the children for their help and advice when he was a tourist in their local environment in Australia. The children were very pleased to receive his postcard, and responded to him with postcards they created themselves. Within the limited space of the postcard, they had produced colourful, detailed pictures and considered verbal descriptions. Our collaborative reflection on this event included examining the use of postcard-sized paper to encourage detailed drawings and written information in a limited time period, and the possibility of introducing an authentic task as a way of engaging children in the research.

Keeping in role, one of the researchers returned to the class, explaining that she had enjoyed Australia so much that she had travelled here again from Canada. The conversation moved to the postcard the class had received from Scotland and the postcards they had sent to the Scottish researcher.

The researcher suggested that children in Canada might also be interested in learning about their local environment. The class decided to make postcards for Canadian children. Paper was cut to the size of a large postcard and children used the variety of drawing materials available in the classroom. They easily filled the card and were eager to dictate and/or write stories to the Canadian children. For example, one student drew a colourful and detailed picture of trees and buildings (Figure 8 below) and wrote: "I'm planting 2000 more Honeygold Mangoes. I have lots of trees. We've got a Playstation. I live on a farm. There's lots of tractors on our farm. We're making bigger sheds." 


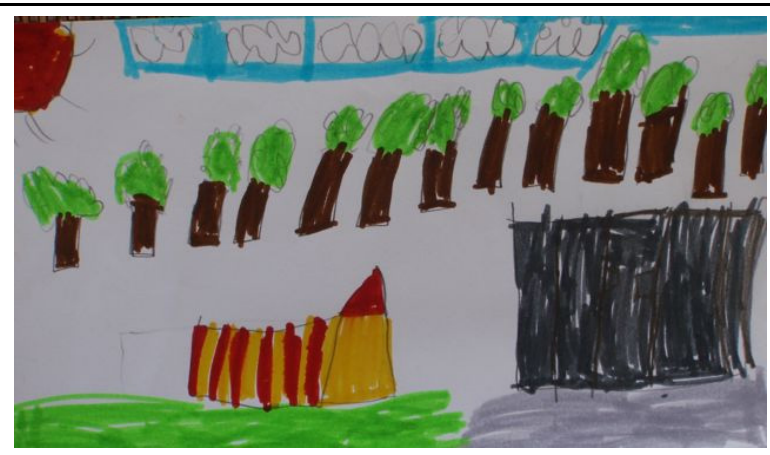

Figure 8 .

Reflections of this research visit suggested to us that the size of paper should be smaller, with the large postcard-size seeming to elicit detailed drawings and stories. The authentic task, that is, having a target audience with a genuine interest in their drawings and stories, seemed to encourage children to express their thoughts and understandings, thus producing rich data. With the smaller sized paper, time periods of 20 minutes to $1 / 2$ hour seemed suitable. Ideally, we felt that it would be beneficial to have a similar-aged class overseas who could receive these postcards and send back postcards of their own. This would provide rich, cross-cultural data and also benefit the child participants.

\section{Discussion}

The purpose of this study was to test how an arts-based methodology could be used to determine children's perceptions of their environment. We had to overcome the barrier of not having a guide to instruct us on how to do so. Therefore, not only did our study seek to determine the value of the Arts (drawing and story-telling) as data collection tools, but also what we found effective and ineffective when implementing visual methods. The key learnings we gleaned about art-based data collection strategies for eliciting children's perceptions of their environment could be categorised under the headings of: Drawing and Support Materials, Storytelling, Time, Prior Knowledge and Children's Interests. Each of these issues is summarised below.

\subsection{Drawing and Support Materials}

Originally, the use of three, A4 sized rectangles for the drawings seemed restrictive, resulting in the upsizing of paper to A3 sheets. However, we soon discovered it was too difficult for children to fill paper of an A3 size, with drawing materials other than paint and thick paintbrushes. While we would certainly consider A3-sized paper if paint were included as a drawing material, for data collection with coloured pencils, crayons and felt-tipped markers, we have had the greatest success with large postcard-sized paper. In the future we will provide enough materials for each child to have a complete selection of colours and types of materials.

The use of the Window book and the cardboard windows seems to have influenced children's drawings, with many children drawing window frames and repeating issues from the book. A more helpful support, seemed to be the provision of an audience, who would receive the drawings and in doing so learn about the children' natural environment. This could lead to international data collection and comparison, as mentioned above.

\subsection{Storytelling}

Until children were required to tell stories to support their drawings, it was difficult to determine all of what was included in the drawings and thoughts behind the drawings. We found that children's stories accompanying their drawings provided further information about the drawings, thus contributing to our interpretation of them. In future data collection we will request that stories accompany all art works.

\subsection{Time}

Time allocated to drawings varied from 20 minutes to well over an hour per drawing. With the use of A3 or even A4 paper, extended periods of drawing still did not ensure that the picture was completed. In the future as we use the large postcard format and the drawing materials stated above, we will allow children up to $1 / 2$ hour per art work, with the option of extending the time if it is required.

Not all children understood the concept of "the future" or "in 20 years". With further data collection, we will try to explain the concept of the future in terms that children understand, and accept that not every child will be able to conceptualise the future. 


\subsection{Prior Knowledge}

Some children demonstrated an understanding and/or interest in environmental sustainability issues based on prior teaching. Future data collection will include asking classroom teachers what they have taught their children about environmental sustainability prior to data collection. In addition it would be useful to question the children themselves about whether they have learned anything about environmental sustainability from sources within or outside the school. In the situation that children do bring (prior knowledge) to the study, it will not be seen as a limitation or weakness, but rather evidence that children's learning and experiences occur in a variety of contexts.

\subsection{Children's Literal Expressions and Interests}

A number of children's interests were presented in all locations throughout the stages of our data collection. The first was that when asked to draw what they saw from their windows, many children drew literally what they saw, including a large fence (Figure 2), a drinking fountain, the local church, etc.

Children also depicted images of interest such as Thomas the Tank Engine. Anning \& Ring (2004) state that children's sense of aesthetics are partly culturally acquired by immersion in popular culture...it is clear that they develop strong personal preferences for what they want to draw and how they want to draw it. Children's representations of their interests, rather than their environments as the task instructed, provide justification for Anning \& Ring's (2004) findings of children's strong personal preferences. In the future, we would consider asking children to share a story about their interest to determine if this interest in some way informs their perceptions of the environment, or whether they are just off task. In the situation they are off task, instructions will be reworded, considering this point.

\section{Conclusion}

Movement towards a sustainable society can be achieved through education (United Nations Educational, Scientific and Cultural Organisation [UNESCO], 2009). Transformation of the educational system could involve increasing the value of the Arts (including storytelling), so that they may be used collaboratively with science to elicit children's environmental understandings. Indeed, "many art educators today advocate a teaching philosophy that encourages children to think about the relationship of art, ecology and community" (Hurwitz and Day, 2008, p.19). Payne (1998) argued that environmental education would be more relevant and effective if "teachers understood better how children see and conceive nature, so that learning could be more grounded in the reality of children's conceptual frameworks" (cited in Martin, 2007, p.58).

This paper has presented five arts-based strategies we have trialled and refined to assist children in communicating their perceptions of the natural world. Our journey has taken us to a number of classrooms, age groups and countries, providing us with many opportunities to reflect and learn, and reinforced our belief that the arts can be implemented as data collection tools, to glean children's understandings of the environment.

Based on our exploration, we recommend that visual art expression, such as drawings, be accompanied by other arts forms such as dramatization and storytelling, to elicit rich data. We also identify the important role and impact that drawing and support materials, storytelling, time, prior knowledge, literal expressions and interests play in not only children's ability to represent their ideas but also on how they represent these.

Our findings suggest that there is value in the juxtaposition of arts and science in collecting data about children's understandings of their environment and environmental sustainability. We look forward to future data collection, using the strategies we have developed through the cycles of this action research project.

\section{References}

Alerby, E. (2000). A Way of Visualising Children's and Young People's Thoughts about the Environment: a study of drawings. Environmental Education Research, 6(3), 205-222.

Anning, A., \& Ring, K. (2004). Making Sense of Children's Drawings. Berkshire, England: Open University Press.

Barraza, Laura (1999) Children's Drawings About the Environment, Environmental Education Research, 5(1), 49-66.

Benson, C. (2009). Changing Places: Children's Experiences of Place during Middle Childhood. Unpublished doctoral dissertation, Humboldt State University.

Blizard, C. R., \& Schuster, R. M. (2007). Fostering Children's Connections to Natural Places through Cultural 
and Natural History Storytelling. Children, Youth and Environments, 17(4), 171-206.

Bowker, R. (2007). Children's Perceptions and learning about tropical rainforests: an analysis of their drawings. Environmental Education Research, 13(1), 75-96.

Butler, M. (2008). Window on a Changing World. Classroom Magazine. Retrieved November 9, 2008, from http://www.jeanniebaker.com/focus_web/window_on_a_changing_world.htm

Chawla, L. (2007). Childhood Experiences Associated with Care for the Natural World: A Theoretical Framework for Empirical Results. Children Youth and Environments, 17(4), 144-170.

Cornett, C. E. (2007). Creating Meaning Through Literature and the Arts: An Integration Resource for Classroom Teachers. ( $3^{\text {rd }}$ ed). New Jersey, USA: Pearson.

Denscombe, Martyn. (2007). The Good Research Guide for small-scale research projects. ( $3^{\text {rd }}$ ed). Berkshire, England: Open University Press.

Department of Families, Housing, Community Services and Indigenous Affairs [FaHCSIA]. (2009). On PAR Using Participatory Action Research to Improve Early Intervention. Retrieved March 1, 2011, from http://www.fahcsia.gov.au/sa/housing/pubs/homelessyouth/on_par/Documents/Participatory_Action_Resear $\mathrm{ch} / \mathrm{sec} 1 . \mathrm{htm}$

Drew, W. F., \& Rankin, B. (2004). Promoting Creativity for life using Open-Ended Materials. Young Children. $1-8$.

Edwards, L. C., \& Nabors, M. L. (1993). The creative arts process: What it is and what it is not. Dimensions, 48(3), 77-81.

Elliott, S. (2003). Patches of Green - Early Childhood Environmental Education in Australia: scope, status and direction. Sydney, NSW: Environment Protection Authority.

Ewert, A., Place, G., \& Sibthorp, J. (2005). Early-life outdoor experiences and an individual's environmental attitudes. Leisure Sciences, 27, 225-239.

Hurwitz, A., \& Day, M. (2001). Children and Their Art: Methods for the Elementary School. ( $7^{\text {th }}$ ed.). Belmont, USA: Thomson.

Huss, E., \& Cwikel, J. (2005). Researching creations: Applying arts-based research to Bedouin women's drawings. International Journal of Qualitative Methods, 4(4), Article 4. Retrieved August 1, 2011, from http://www.ualberta.ca/ iiqm/backissues/4_4/pdf/huss.pdf

Kendrick, M., \& Mckay, R. (2004). Drawings as an Alternative Way of Understanding Young Children's Constructions of Literacy, Journal of Early Childhood Literacy, 4, 109-128.

Knight, L. (2008). Communication and Transformation through Collaboration: rethinking drawing activities in early childhood. Contemporary Issues in Early Childhood Journal, 9(4), 307-316.

Kress, G. (2000). 'Multimodality'. In B. Cope \& M. Kalantzis (eds), Multiliteracies: Literacy Learning and the Design of School Futures (pp.182-202). London: Routledge.

Kyle, G., \& Chick, G. (2007). The Social Construction of a Sense of Place. Leisure Sciences, 29, 209-225.

Lincoln, Y. S., \& Guba, E. G. (1985). Naturalistic Inquiry. Beverley Hills, California: Sage Publications Inc. Influence Children's Attitudes to the Environment? Primary Educator, 5(1), 23.

Linon, J., Outhred, L., \& Farrell, J. (1999). Cry Me a River: Can Literature

Martin, P. (2007). Caring for the Environment: Challenges from Notions of caring. Australian Journal of Environmental Education, 23, 57-64.

Millennium Ecosystem Assessment. (2005). Ecosystems and Human Well Being: Synthesis. Washington, DC, USA: Island Press.

Mullen, C. (2003). A self fashioned gallery of aesthetic practice. Qualitative Inquiry, 9(2), 165-182. 
Newman, F., Marks, H., \& Gamoran, A. (1995). Authentic Pedagogy: Standards that Boost Student Performance. Issues in Restructuring Schools, 8, 1-17.

Olli, E., Grendstad, G. and Wollebaek, D. (2001) Correlates of environmental behaviours: Bringing back social context. Environment and Behavior, 33, 181-208.

Rose, G. (2007). Visual Methodologies: An Introduction to the Interpretation of Visual Materials (2 ${ }^{\text {nd }}$ ed.). Los Angeles, London, New Delhi, Singapore \& Washington DC: Sage Publications.

Russell-Bowie, D. (2012). MMADD about the arts! An Introduction to Primary Arts Education. Frenchs Forest, NSW: Pearson Education.

Somerville, M. (2008). Bubbles on the Surface: a methodology of water. Refereed conference publication, Australian Association for Research in Education Annual Conference, Brisbane, Qld.

Sorin, R. (2004). Understanding children's feelings - Emotional literacy in early childhood. Research in Practice Series. Canberra: Early Childhood Australia. ISBN: 0975193546.

Steadman, R.C. (2002) Towards a social psychology of place: Predicting behaviour from place-based cognitions, attitude, and identity. Environment and Behaviour, 34, 561-581.

Tassoni, P. (2007). Making their Mark: Children's Early Writing. London: British Association for Early Childhood Education.

Torzillo, M. (2009). Just Go Crazy with Dance: The Value of Dance in Secondary School. Unpublished dissertion. James Cook University.

United Nations Educational, Scientific and Cultural Organisation. (2009). UNESCO Review of Contexts and Structures for Education for Sustainable Development 2009. Paris, France: Arjen Wals.

Villacorta, M., Koestner, R., \& Lekes, N. (2003). Further validation of the motivation toward the Environment Scale. Environment and Behaviour, 35, 486-505.

Westoby, M. (1993). Biodiversity in Australia compared to other continents. In R. E. Ricklefs \& D. Schluter (eds), Historical and Geographic Determinants of Community Diversity. Chicago: University of Chicago Press.

White, R. (2004). Young Children's Relationship with Nature: Its Importance to Children's Development \& the Earth's Future. Kansas City, USA: White Hutchinson Leisure and Learning Group.

Wright, S. (2001). Drawing and storytelling as a means for understanding children's concepts of the future. Futures, 6(2), 1-20.

Wright, S. (2007). Young Children's meaning making through drawing and storytelling. Australian Journal of Early Childhood, 13(4), 37-48.

Wright, S. (2008). Young Children's meaning making through drawing and 'telling': Analogies to filmic textual features. Australian Journal of Early Childhood, 32(4), 37-48.

Wright, S. (2010). Understanding Creativity in Early Childhood. London: SAGE. 